\title{
Voluntary Sustainability Report AsSurance By the Fortune 100
}

\author{
Michael f. Fischer, Carol M. Fischer, and Matthew R. Bizzaro
}

Michael J. Fischer (mfischer@sbu.edu) and Carol M. Fischer (cfischer@sbu.edu) are both Professors, and Matthew R. Bizzaro (bizzarmr13@bonaventure.edu) is a student, in the St. Bonaventure University School of Business, St. Bonaventure, NY 14778. Correspondence regarding this paper can be directed to Michael J. Fischer.

The authors are grateful for financial support for this research provided by the McQuade Center for Accounting Excellence at St. Bonaventure University.

\begin{abstract}
Companies are increasingly choosing to voluntarily issue sustainability, or corporate social responsibility, reports as a supplement to their annual financial reports. Recent publications have also reported on the related phenomenon of sustainability report assurance. Few if any studies, however, have begun to examine the assurance of sustainability reports in any detail. The study reported in this paper contributes to increasing the understanding of sustainability report assurance. Specifically, the paper reports on an examination of the recent sustainability reporting practices
\end{abstract}


of the Fortune 100 companies. The study identifies the companies that did and did not issue sustainability reports; those that were and were not accompanied by an independent assurance report; the providers of the assurance services; and the assurance standards followed. Conclusions and recommendations for future research are provided.

KeyWords: sustainability reporting, corporate social responsibility, assurance

Data Availability: Data used in this study are available from public sources

DOI: http://dx.doi.org/10.15239/j.brcadvjb.2018.03.01.ja02

\section{InTRODUCTION AND LITERATURE REVIEW}

Issues of corporate social responsibility and sustainability have attracted a great deal of attention in both the academic and practitioner business literatures for many years. While no single, generally agreed-upon definition of corporate social responsibility (CSR) or sustainability yet exists (on this point, see e.g., Sheehy, 2015), the following seems to capture many of the important elements; CSR reflects:

a company's commitment to operating in a socially, economically and environmentally sustainable manner, while recognizing the interests of its stakeholders. (PwC, 2010, p. 51)

Systematic sustainability reporting has not been in existence for as long as have general discussions regarding sustainability and corporate social responsibility. Nevertheless, sustainability reports have been issued by a variety of companies for some time. Regarding the prevalence of CSR reporting, $\mathrm{PwC}$ indicated in 2010 that "CSR reports are becoming an integral part of a company's relationship with employees, suppliers, customers, investors and communities" (p. 2), and reported that $81 \%$ of the 423 companies they studied had CSR information on their websites 
(p. 3). Similarly, by 2013 KPMG indicated in its Survey of Corporate Social Responsibility Reporting that "the debate on whether companies should report on CR [Corporate Responsibility] is dead and buried" and in the $21^{\text {st }}$ century, CR reporting is-or should be-an essential management tool” (p. 9). In that same report, KPMG defined CR reporting as:

the process by which a company can gather and analyze the data it needs to create long term value and resilience to environmental and social change. CR reporting is essential to convince investors that your business has a future beyond the next quarter or the next year. $(2013$, p. 9)

Publications calling for and describing sustainability and related types of reporting have been emerging in recent years. Perhaps among the most recognized, at least for its title, is The Triple Bottom Line published by Savitz and Weber in 2006. The "triple bottom line" calls for companies to report on (and actively manage) their economic, environmental, and social performance.

A relatively sizeable literature has developed in recent years regarding various aspects of CSR or sustainability reporting ${ }^{1}$. For example, papers have provided overviews of sustainability reporting (e.g., Verschoor, 2012; Monterio, 2014, 2015; Dzinkowski, 2015); addressed technical aspects of sustainability reporting (e.g., Fornaro, 2011; Monterio, 2010a $\&$ b; Thomas, 2015); provided reviews of the literature in this area (e.g., Unerman \& Chapman, 2014; Huang \& Watson, 2015; Moser \& Martin, 2012; Ramanna, 2013); provided examples of sustainability reporting by one or a small number of companies (e.g., Borkowski, et al., 2010; Busco, et al., 2014); and examined various correlates of sustainability reporting, such as relationships between sustainability reporting and cost of capital (e.g., Dhaliwal, et al., 2011), analyst forecast error (e.g, Dhaliwal, et al., 2011, 2012), and earnings management behavior (e.g., Kim, et al., 2012). Nevertheless, there have been relatively few systematic examinations of the sustainability reports actually issued by large samples of companies. 
Fewer authors have examined the phenomenon of sustainability report assurance; a brief review of the extant publications relevant to the current study follows. In a fournal of Accountancy article in 2013, Lynch $^{2}$ provided an overview of the growth in the prevalence of independent assurance reports accompanying sustainability reports. Specifically, it was reported that $56 \%$ of the 250 companies in the top half of the Fortune Global 500 list issued sustainability reports in 2008. Lynch also indicated that accounting firms performed $52 \%$ of those assurance engagements.

Pflugrath, et al. (2011) reported on a behavioral experiment with financial analysts in Australia, the United States, and the United Kingdom as subjects. The research instrument included selected financial and CSR information, as well as assurance reports, for two fictitious companies. The research results indicated that "the credibility of a CSR report is greater when it is assured and when the assurer is a professional accountant” (2011, p. 239).

A set of articles were published in a 2015 Auditing: A fournal of Practice \& Theory (AFOPAT) forum on CSR and assurance, four of which are particularly relevant to this study. Casey and Grenier (2015) reported on what they described as the "enigma" of CSR assurance (CSRA) services in the US: that the level of voluntary assurance of sustainability reports sought by US firms significantly lags that of their international counterparts. Their study found demonstrable benefits to sustainability report assurance, including particularly that "CSRA is associated with a reduction in the cost-of-capital along with lower analyst forecast errors and dispersion" (p. 100). They concluded their paper by stating that "our study suggests that the scarcity of CSRA in the U.S. is puzzling, as it is reasonable to speculate that many U.S. firms would benefit from CSRA, but are currently not obtaining it" (p. 100). Casey and Grenier's methodology did not include the direct examination of either CSR or CSRA reports; rather just whether those reports were or were not issued by the studied firms.

Two experimental studies published in the 2015 AFOPAT forum also reported evidence of benefits to voluntary sustainability report assur- 
ance. In an experiment involving investors, Brown-Liburd and Zamora (2015) examined "the role of CSR assurance when information on CSR investment level is integrated with information on whether managerial pay is explicitly tied to sustainability" (p. 75). They reported their finding that "in the presence of pay-for-CSR performance and high CSR investment level, investors' stock price assessments are greater only when CSR assurance is also present” (p. 75). Based on an experiment involving graduate students in a financial analysis course, Cheng, et al. (2015) found "evidence that assurance increases investors' willingness to invest to a greater extent when ESG [Environmental, Social, and Governance] indicators have high relevance to the company's strategy... [and that] the assurance of ESG indicators has a beneficial signaling role in communicating the importance of this reported information to investors" (p. 131). Both studies manipulated just the presence or absence of an independent assurance report.

Finally in the AFOPAT forum, Peters and Romi (2015) used archival information to examine whether the presence and characteristics of a Board of Directors' sustainability committee and a Chief Sustainability Officer (CSO) impact the voluntary assurance of corporate sustainability reports. Based on their study they report that (1) "the presence of a CSO is positively associated with corporate sustainability report assurance services, and that this association increases when the CSO has sustainability expertise" (p. 163); (2) "only those environmental committees containing directors with greater expertise influence the likelihood of obtaining assurance services" (p. 163); and, (3) "environmental committees with greater expertise appear to prefer the higher-quality assurance services of professional accounting firms. Expert CSOs, on the other hand, prefer assurance services from their peers with sustainability expertise" (p. 163). Assurance reports were not examined in any detail in this study; rather, just the presence or absence of a report and the nature of the provider were noted. 
In summary, the existing literature suggests that there may be benefits to companies that voluntarily seek independent assurance of their published sustainability reports. However, these studies have operationalized "assurance" at a relatively unsophisticated level. Without further information it is hard to know whether this mirrors reality, or whether there is much greater variation in practice than what these studies would suggest. Further, there is a current lack of understanding of the companies that choose to seek voluntary assurance of their sustainability reports, their choices of independent assurers, or the assurance standards that are followed in these examinations.

Given that much of the existing research has examined international companies, and has found evidence of differences from the sustainability reporting behavior of U.S. companies, the decision was made to focus this study on the sustainability assurance choices made by large U.S. companies.

The following section describes the specific research questions pursued in this study and the research method applied; the subsequent section then presents the research findings; and the final section provides a summary and conclusions, including recommendations for future research.

\section{Research Questions And Methods}

The overall objective of this study was to advance our understanding of the choices made by companies regarding voluntary assurance of their sustainability reports. Specifically, the study sought to increase our understanding of the answers to the following questions:

1. What percentage of companies voluntarily seek assurance on their sustainability reports?

2. Who serves as the independent assurers for these companies?

3. What assurance standards are followed? 
We also sought to begin understanding the factors that may affect companies' choices to seek voluntary assurance of their sustainability reports.

Since the publication of King's seminal study showing a relationship between industry and stock price behavior (King, 1966) it has been common to examine or control for industry effects in studies of accounting choice. While there are no extant studies that have established a relationship between a company's industry and its decision to obtain independent assurance on its sustainability report, we chose to examine this sample for the presence of an industry effect.

Accounting firms have been increasingly active in the sustainability reporting arena (see Deloitte, 2016; EY, 2014; KPMG, 2017; and PwC, 2016 for examples of publications by the "Big 4" CPA firms). While there has been less published by the various firms regarding sustainability report assurance, we questioned whether a company's financial statement auditor may influence their decision to seek voluntary assurance on their sustainability report.

Our examination of the data for an association between sustainability report assurance choice and either industry or financial statement auditor is reflected in the fourth and final, exploratory research question:

4. Is sustainability report assurance choice associated with either industry or financial statement auditor?

While a wide variety of companies issued sustainability reports during the period under examination, the choice was made to focus this study on the largest U.S. companies. More specifically, the reporting behavior of the first 100 companies in the 2015 Fortune 500 (hereafter referred to as the "Fortune 100") (Fortune, 2015) was examined. A systematic search was undertaken for the sustainability reports publicly issued by these companies. The most recent sustainability report of each issuing company was obtained and utilized in this study; in most cases, this report was for the company's 2015 fiscal year. 
16 BRC Journal of Advances in Business Vol. 3, No. 1

\section{Preview Complete}

This completes the limited preview of this paper. Please visit the link below to purchase.

\section{Citation Information}

Fischer, Michael J., Carol M. Fischer, and Matthew R. Bizzaro. "Voluntary Sustainability Report Assurance by the Fortune 100." BRC fournal of Advances in Business 3, no. 1 (2018): 15-33. http://dx.doi.org/10.15239/ j.brcadvjb.2018.03.01.ja02

\section{Web APPEndix}

A web appendix for this paper is available at: http://dx.doi.org/10.15239/ j.brcadvjb.2018.03.01.wa02 